\title{
The Role of Perceived Utilitarian and Hedonic Value in Predicting Use of Location-Based Anonymous Social Networking Sites
}

\author{
Priyanka Khandelwal ${ }^{1 *}$ \\ (D) 0000-0002-8616-7009 \\ Melissa R. Gotlieb ${ }^{2}$ \\ (D) 0000-0002-6558-7055 \\ ${ }^{1}$ West Texas A\&M University, USA \\ 2 Texas Tech University, USA \\ * Corresponding author: pkhandelwal.research@gmail.com
}

Citation: Khandelwal, P., \& Gotlieb, M. R. (2021). The Role of Perceived Utilitarian and Hedonic Value in Predicting Use of Location-Based Anonymous Social Networking Sites. Online Journal of Communication and Media Technologies, 11(4), e202118. https://doi.org/10.30935/ojcmt/11114

\section{ARTICLE INFO}

Received: 20 Jan 2021

Accepted: 14 Jun 2021

\section{ABSTRACT}

Recent years have seen a rapid rise in the popularity of location-based anonymous social networking sites (LB-ASNS). Although anonymity and site specificity have been reported to be the major attractions of these platforms, there exists a severe paucity of studies that have investigated the adoption behavior of LB-ASNS using the Technology Acceptance Model as the primary theoretical framework. The goal of this study is to utilize an extended version of TAM to explain the actual use of LB-ASNS. We demonstrate the applicability of TAM in the realm of LBASNS. Our results suggest that the quality and enjoyment afforded by these platforms are major predictors of actual use.

Keywords: location-based anonymous social networking sites, adoption behavior, TAM, college students, hedonic value

\section{INTRODUCTION}

The popularity of anonymous social networking apps has increased over the years. In fact, Gerhart and Koohikamali (2019) reported there is a growing trend among young users to migrate away from traditional, non-anonymous social networking sites (SNS) (e.g., Facebook, Twitter) and gravitate toward anonymous social networking apps (e.g., Whisper, Anomo).

Non-anonymous SNS almost always require users to create a profile and encourage them to share identifiable information. Once users begin generating content on these platforms, their activities become anchored to their profiles often allowing third-party vendors to track their entire feed. Thus, users need to exercise a high level of discretion if they wish control the flow of information in traditional SNS. The limited ability of users to control the downstream use of their personal information has given rise to growing privacy concern in mainstream SNS (Golbeck \& Mauriello, 2016). Consequently, the appeal of alternative platforms that are perceived to provide greater privacy protection has increased. For example, Choi and Sung (2018) reported that Snapchat users are less likely to be concerned about sharing personal information over this platform as compared to Instagram users.

The advent of anonymous social networking sites (ASNS), in particular, has allowed users to generate content without being anchored to any meaningfully identifiable profile. Additionally, ASNS offer technical anonymity to their users from others in the sense that the platforms claim not to share the personal information of their users with third parties under ordinary circumstances. Furthermore, ASNS, by design, do not support persistent social links among their users. In most cases, these platforms do not engage in tracking 
content generated by users and have limited archival capabilities (Ayyagari et al, 2011). Increased awareness of privacy issues in the post-Snowden era and the perception that ASNS are designed to protect the privacy of their users have resulted in a steady expansion of the user base of ASNS over the years (Wang et al., 2014).

Moreover, location based (LB) variants of ASNS offer their users a unique combination of anonymity and proximity to experientially relatable actors. The localization phenomenon (Saker \& Evans, 2016) of LB-ASNS induces users to perceive the feeds generated in their chosen local message boards as proxies for their physical environments and allows them to "feel" that their physical space is "filled" with the people who are generating content in the LB-ASNS (Frith \& Saker, 2017). This perceived relational proximity allows users to be a part of the local community and jointly comprehend their physical locality. In other words, the locationbased feeds in LB-ASNS offer the users a tool to keep a tab on the "pulse" of their chosen location (Frith \& Saker, 2017).

As users increasingly gravitate toward LB-ASNS, understanding the factors that contribute to its adoption and use has become increasingly important, as both anonymity and proximity have important consequences-both positive and negative-on disinhibition, self-disclosure, and psychological well-being (Frith \& Saker, 2017; Peter \& Valkenburg, 2011; Valkenburg \& Peter, 2011; Vossen \& Valkenburg, 2016). Although previous studies have examined the factors that explain the switch from mainstream SNS to ASNS (Gerhart \& Koohikamali, 2019) as well as attitudes toward LB-SNS (Koohikamali, Gerhart, \& Mousavizadeh, 2015), to our knowledge the existing empirical literature has not examined the adoption and use of LB-ASNS.

It can be argued that adoption and use of LB-ASNS may stem from both perceived utilitarian and hedonic value. While use of LB-ASNS help users to keep themselves informed about their locality (Frith \& Saker, 2017), they also inherit the hedonic aspects of general SNS (Ramirez-Correa et al., 2019) and consequently may be used to derive enjoyment rather than enhance productivity.

To examine the adoption and use of LB-ASNS, we join the tradition of scholars who have applied the Technology Acceptance Model (TAM) to the study of traditional, non-anonymous SNS (Lorenzo-Romero \& Constantinides, 2011) to examine how socio-technological (i.e., users' perceptions of the platform, their competence in using the platform, and societal norms regarding use of the platform) and motivational factors (i.e., perceived usefulness, perceived ease of use, and attitude toward the technology) contribute to the adoption and use of LB-ASNS. Specifically, by including perceived affordance and perceived playfulness (i.e., perceptions of the platform), as important antecedent variables, TAM allows us to examine the potential dual nature of LB-ASNS, thereby providing insight into its implicit value from both utilitarian and hedonic perspectives.

This study uses a survey of college students to examine the adoption and use of LB-ASNS. Specifically, this study examines the relationships among the factors in TAM in the specific context of Yik Yak. Although this platform ceased operation in 2017, we contend that investigation into its adoption and use holds relevance and importance for more broadly understanding the adoption and use of LB-ASNS.

\section{LITERATURE REVIEW}

\section{Anonymous Social Networking Sites}

As young adults migrate toward ASNS in search of anonymity and privacy, concern has emerged among scholars regarding the potential for increased cyberbullying. Specifically, they suggest the "toxic" disinhibition and lack of accountability among users contributes to the generation of abusive content on these platforms (Moore et al., 2012). Not surprisingly, human tragedies (e.g., suicide of Hannah Smith in 2013 and that of Ciara Pugsley in 2012) caused by such cyberbullying on ASNS (Hall, 2013) have espoused a generally negative rhetoric surrounding these platforms (Lauri \& Farrugia, 2020).

Although the use of ASNS comes with the risk of cyberbullying, it is important to also acknowledge its benefits. In particular, the higher degree of anonymity offered by ASNS affords its users the opportunity to explore their identities and experiment with new behaviors without any substantial fear of social consequence (Li \& Literat, 2017). This "benign" disinhibition can promote higher levels of self-disclosure (Clark-Gordon et al., 2019), which benefits individuals emotional and psychological well-being (Posteuca-Esi, 2019). Furthermore, such disinhibition can also empower users by offering a means for recovery, catharsis, and 
autonomy (Pedersen, 1997). This empowering aspect of ASNS appears to be enticing to young adults-largely college students-during a critical and tumultuous period of their lives that requires extensive social adjustments (Black, Mezzina, \& Thompson, 2016). Indeed, research has shown that perceived freedom of expression (Gerhart \& Koohikamali, 2019) and the desire for more privacy and a space away from adults help to explain the migration from non-anonymous SNS to ASNS (Black, Mezzina, \& Thompson, 2016; Boyd \& Marwick, 2011; Madden et al., 2013).

The support of "benign" disinhibition may be a particularly important aspect of social media platforms used by college-aged students. As Chen (2004) noted, students can develop a strong sense of community on college campuses if they are provided with an environment where free expression is encouraged and their individuality is respected. Indeed, LB-ASNS can provide such an environment (Clark-Gordon, Workman, \& Linvill, 2017). This potential ability of LB-ASNS to help build and strengthen communities by providing opportunities for expression further indicates the importance of considering the utilitarian aspects of LBASNS in order to predict its adoption and use, particularly in college campuses.

A now-defunct location-based social networking platform, Yik Yak, provides an interesting case study. Qualitative results reported by Vaterlaus (2017) indicated that college students used Yik Yak for informational, entertainment, agency-enhancement and community-building purposes. Frith and Saker (2017) also agreed that this platform indeed catered to the utilitarian and hedonic demands of its users. Initially, it appeared Yik Yak was versatile enough to become a genuine dual-purpose LB-ASNS. However, it became increasingly embroiled into controversial use of its anonymity functionality which played a crucial role in its dissolution in 2017. Consequently, examining this digital platform offers us an opportunity to juxtapose the utilitarian and hedonic aspects of LB-ASNS and broaden our understanding of the adoption and continued use of these platforms.

We, therefore, reiterate that our goal is to examine the relative contribution of perceived utilitarian and hedonic value in predicting the adoption and use of dual purpose LB-ASNS. We propose to conduct this investigation from the theoretical perspective of the Technology Acceptance Model (TAM). We also note that very few studies have utilized TAM as the primary theoretical framework to analyze the adoption behavior and use of ASNS (Al-Qaysi, Mohamad-Nordin, \& Al-Emran, 2020). Our study addresses this paucity of literature on the application of TAM in the realm of LB-ASNS.

\section{Technology Acceptance Model}

The Technology Acceptance Model (Davis, 1989) has turned out to be the "prevailing theoretical approach regarding users' adoption to social media" (Wirtz \& Gottel, 2016, p. 98). Particularly, in the context of SNS, Lorenzo-Romero and Constantinides (2011) argued that TAM should be used to explain SNS adoption because its versatility and flexibility allow TAM to predict the adoption of any technology effectively.

TAM is extensively used for understanding users' acceptance of new technology, particularly in the domain of information systems. It posits that actual adoption and consistent use of a technology is determined by users' motivation to use the said technology. Motivation in this context can be explained by three constructs: (a) Perceived usefulness-the relative advantage of using a new technology over the extant ones, (b) Perceived ease of use-the amount of cognitive effort required to use a technology, and (c) Attitude toward using the technology —an evaluative response to the said technology (McGuire, 1969). When the decision to adopt technology is voluntary, attitude toward using the technology turns out to be most influential in determining its use (Kapoor et al., 2014).

The main reasons for the popularity of this theoretical framework for understanding the adoption behavior of new technology are its parsimony, generalizability, high internal validity of its constructs and, perhaps most importantly, its flexibility (Liu, 2010). However, depending upon the technology in question, the basic motivational constructs of TAM-perceived usefulness, perceived ease of use, and attitude-may not be sufficient to explain actual use of the technology (Benbasat \& Barki, 2007). Consequently, TAM has been extended by including various user-specific and technology-specific antecedent variables and constructs.

For instance, in the context of e-commerce, Gefen, Karahanna, and Straub (2003) studied consumer intentions to patronize electronic retail sites. They introduced "trust" and trust-based antecedent variables to 
enrich the original form of TAM and proceeded to utilize trust, perceived usefulness and perceived ease of use to predict consumers intension to use e-retailing websites.

In the context of marketing, Ritz, Wolf, and McQuitty (2019) successfully integrated TAM and the do-ityourself behavioral model to explain small business' motivation to participate in digital marketing campaigns. They used the TAM constructs of perceived usefulness and perceived ease of use to predict small business owners' intention to use digital marketing campaigns. The "intention to use" variable was then integrated with perceived economic benefit, perceived lack of quality, and perceived lack of availability to predict the actual use of digital marketing by small businesses. Their results revealed the ability of TAM constructs to predict the actual use of digital marketing among small businesses.

In the context of customer relationship management, Galib, Hammou, and Steiger (2018) utilized an extended version of TAM to predict customers' intention to participate in social customer relationship management programs (sCRM). As predictors, they utilized user satisfaction, perceived enjoyment, customers' perception of risk involved in joining sCRM programs, perceived ease of use, perceived usefulness of sCRM programs, and customers' attitude towards participating in such programs. Their results revealed perceived risk to be an important predictor for the outcome variable.

In the realm of supply chain management, Kamble, Gunasekaran, and Arha (2019) investigated the adoption behavior of blockchain technology through the lenses of TAM, the Technology Readiness Index (TRI), and the Theory of Planned Behavior. They utilized two variables from TRI-perceived discomfort and perceived lack of security (analogous to perceived risk) to predict perceived ease of use. These three variables, along with the TPB construct of subjective norm, were then used to predict perceived usefulness. Finally, subjective norm, perceived usefulness, and attitude toward blockchain technology were integrated with another TPB construct-perceived behavior control to predict the intension to use blockchain technology among supply chain professionals. Their results revealed an association between subjective norm and perceived usefulness.

Several studies also have utilized an extended version of TAM to investigate the adoption behavior of mobile banking systems (Aboelmaged \& Gebba, 2013; Govender \& Sihlali, 2014). In particular, Gumussoy, Kaya, and Ozlu (2018) introduced compatibility, mobility access, and perceived self-efficacy to predict perceived usefulness and perceived ease of use of mobile banking systems. Then they used these TAM constructs, along with subjective norm and perceived risk, to predict intention to use this type of banking system.

To capture the entertainment aspect of the internet, Moon and Kim (2001) introduced perceived playfulness, along with perceived usefulness and perceived ease of use, to predict individuals' attitude and intention to use the World-Wide-Web. Their results revealed that perceived playfulness was an important predictor for both attitude and behavioral intention.

In the context of health-related information systems, Razmak and Bélanger (2018) included "compatibility" and "communicativeness," along with perceived ease of use and perceived usefulness, to predict patients' attitude toward adopting the personal health record systems. Mao and Hovick (2020) used two facets of perceived affordance-perceived editability and perceived persistence-and subjective norm to predict perceived usefulness of online messaging features embedded in online patient portals. Since these portals facilitate direct communication between patients and health care providers, perceived affordances associated with this channel of communication captures its utilitarian value. The results revealed perceived editability and subjective norm can predict perceived usefulness.

TAM has also been used in the context of travel and leisure related information systems. For example, Chen and Tsai (2019) developed a personalized location-based mobile tourism application (PLMTA) and extended the basic TAM by introducing a new variable, perceived convenience. Their results suggested that perceived convenience is a significant predictor for perceived ease of use which in turn is associated with intention to use PLMTA.

Taken together, these studies show TAM has been successfully extended and integrated with different models to understand the adoption behavior of different technologies in different industries under different settings. In general, TAM has continued to evolve as researchers have reported new antecedent variables with significant relationships to the core TAM constructs (for a comprehensive review on the evolution of TAM, 


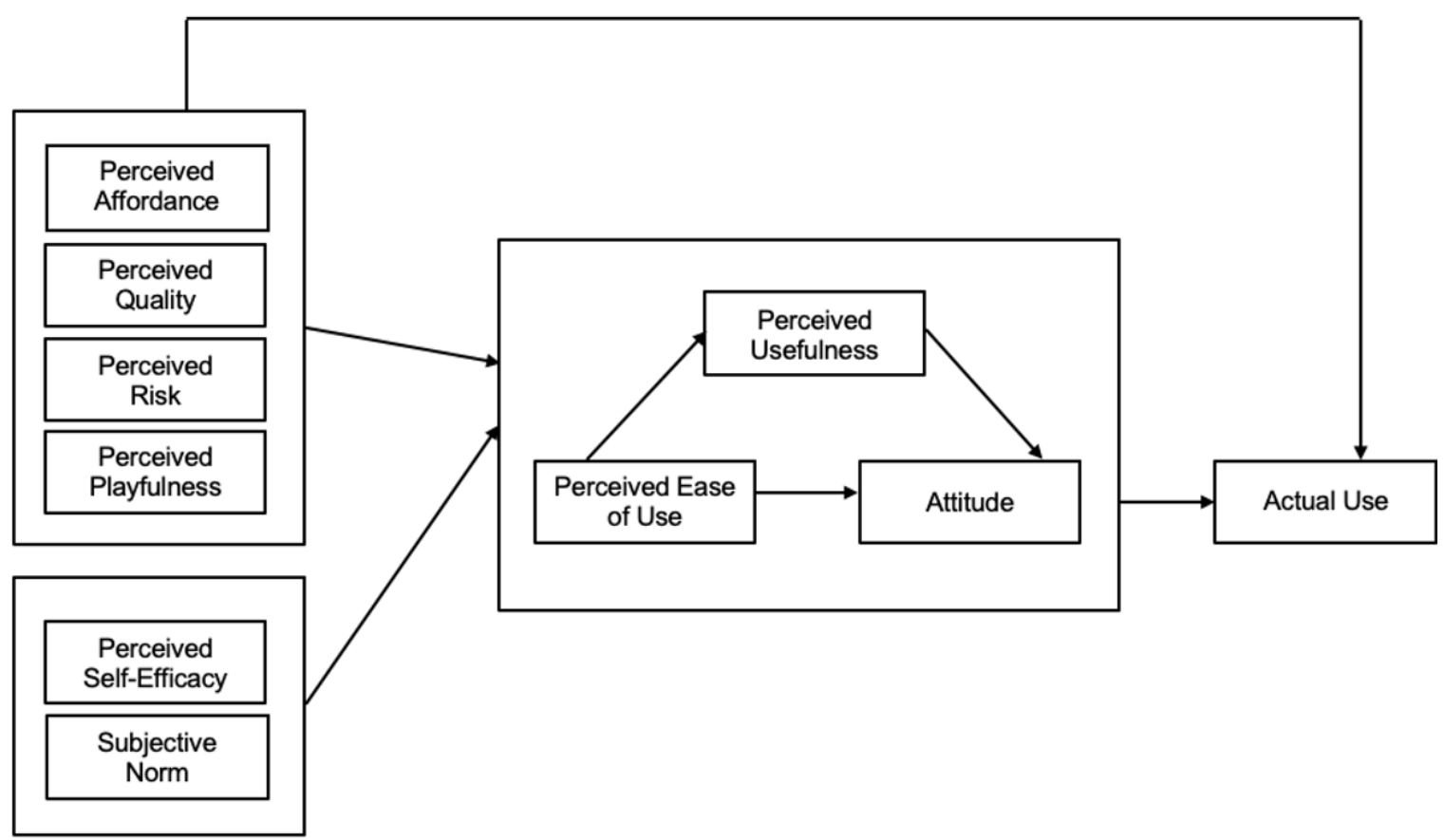

Figure 1. Hypothesized model of location-based anonymous social network site use

please see Lee, Kozar, \& Larsen, 2003; Marangunić \& Granić, 2015). Overall, TAM has become a valuable model; it has accumulated a rich body of research about various forms of technology adoption in a sophisticated and compelling manner (Goodhue, 2007).

Turning to application of TAM in the realm of social media, Al-Qyasi, Mohamad-Nordin, and Al-Emran (2020) conducted a systematic review of 57 research articles, published between 2009 and 2018, that utilized TAM and its extension as the primary theoretical model to understand the adoption behavior of these digital platforms. They reported that perceived enjoyment, subjective norm, self-efficacy, and perceived security were among the most common antecedent variables that were used to extend the core TAM in the realm of social media. However, only one article (Makki et al., 2018) utilized TAM to analyze the usage behavior of Snapchat- an ASNS. To the best of our knowledge this is the first study employing TAM to analyze the adoption and use of LB-ASNS.

\section{RESEARCH MODEL}

\section{Model Construction and Hypothesis Development}

We draw on TAM, and its extensions, to examine how perceptions of the technology, including both perceived affordance and perceived playfulness, along with self-efficacy, and subjective norms contribute to the three motivational constructs described above (i.e., perceived usefulness, perceived ease of use, and attitude toward the technology) to predict adoption and use of LB-ASNS (see Figure 1).

Regarding perceptions of the technology, perceived technology affordance, quality, risk, and playfulness will be considered. More precisely, perceived technology affordances refer to "what an environment offersrelative to the person or group perceiving or recognizing that quality of the environment" (Gibson, 1979, p. 127). This construct emphasizes the importance of consumers' perception of new opportunities (Bradner, 2001; Norman, 1988). Users evaluate new technology not only in terms of technical quality but also in terms of the functions it enables (Norman, 1988). Consequently, users' adoption intention is strongly associated with their perception that the new service would afford possibilities that were previously unavailable (LaRose \& Atkin, 1991). Thus, perceived affordance speaks to users' assessment of the utilitarian aspects of the technology (de la Fuente et al., 2015). Several studies in the domain of human-computer interaction showed how the affordances of SNS have enabled users to utilize these platforms in a multitude of different ways (for a review of technology affordances in SNS, see Murimi, 2018). In particular, Majchrzak et al. (2013) 
demonstrated how technology affordances of SNS enable users to actually use these tools to engage in online conversations on a continual, as-needed basis. In the context of LB-ASNS, perceived technology affordance might include, for example, how these platforms help in the free expression of opinions, aiding development and strengthening of local community, particularly in college campus settings, as a result of the "intertwining of sociality and technology" (Mynatt et al., 1998, p. 130).

Turning to its relationship to the core motivational constructs of TAM, Mao and Hovick (2020) investigated the adoption behavior of messaging features in online patient portals using TAM and reported a positive relationship between perceived technology affordance and perceived usefulness. Tsai, Chang, and Ho (2016) reported a positive association between perceived technology affordance and perceived ease of use in user acceptance of the Memotree system that was designed to encourage family social interaction. Tate and Evermann (2009) posited that the functional affordances offered by a technology form the basis of users' descriptive belief in that technology, which in turn informs users' attitude towards the said technology. Based on the above findings, we expect that perceived technology affordance will be positively associated with constructs measuring users' motivation to adopt LB-ASNS as well as actual use. Accordingly, we posit the following hypotheses:

H1: Perceived technology affordance will be positively associated with (a) perceived ease of use, (b) perceived usefulness, (c) attitude toward LB-ASNS, and (d) actual use.

Next, perceived quality refers to the success of a particular technology, especially pertaining to the virtual world, and is significantly dependent on the desirable characteristics of the technology (DeLone \& McLean, 1992). In particular, the system quality of virtual communities (VC) on the internet, that are expected to serve the needs of members for communication, information, and entertainment, often exhibits a positive relationship with both perceived ease of use and perceived usefulness of VCs (Lin, 2008). Additionally, Kapoor et al. (2014) observed a positive association between perceived quality and users' attitude toward the acceptance of radio-frequency identification integrated systems in libraries. In the context of information systems, Petter et al. (2008) offered a systematic review of literature that identified multiple studies that reported a positive association between perceived system quality and actual system use.

It is important to consider that perceived quality for LB-ASNS potentially emerges from the interaction between anonymity and proximity. The hyper-local nature of LB-ASNS may encourage users to generate content in a certain message board and not in other boards. For instance, Frith and Saker (2019) noted that "multiple participants explained, they only liked using Yik Yak in City A when the population consisted of mostly more liberal college students" (p. 12). This site-specificity of LB-ASNS may be perceived as a quality that is unique to these platforms. Therefore, we proceed to assess whether the positive associations between perceived quality and the motivational constructs of TAM can be corroborated in the specific context of LBASNS. Accordingly, we posit the following hypotheses:

H2: Perceived quality will be positively associated with (a) perceived ease of use, (b) perceived usefulness, (c) attitude toward LB-ASNS, and (d) actual use.

Next, perceived risk refers to the nature and amount of risk perceived by a consumer in contemplating a particular behavior (Bauer, 1960). Despite the popularity of SNS, several studies have reported that the perception of threat to individual privacy among users has increased in these platforms (Madden \& Rainie, 2015; Tsay-Vogel, Shanahan, \& Signorielli, 2018). Biucky and Harandi (2017) reported that the popularity and use of SNS would suffer if users' private data were collected and used without their consent. They found privacy risk to be a significant component of perceived risk, which in turn had a negative association with the perceived usefulness and intention to use social networks. The general negative association between perceived risk and users' attitude towards SNS and frequency of use of SNS has also been reported. CurrásPérez, Ruiz-Mafé, and Sanz-Blas (2013), while examining the association between perceived risk and users' attitude toward SNS, recommended that reduction of the risk is necessary to increase social networking site satisfaction and loyalty among users. Tsay-Vogel, Shanahan, and Signorielli (2018) also found that threat to perceived general privacy and perceived online privacy significantly impacted Facebook use in a negative fashion.

However, since ASNS offer technical anonymity to their users, it can be argued that the lack of risk to privacy will improve the perceived usefulness of these platforms since anonymity reduces fear associated 
with deviation from societal norms and censorship (Pinsonneault \& Heppel,1997; Moore et al., 2012). Furthermore, the anonymity aspect of LB-ASNS does not require users to create profiles. The users can generate content only by offering their location information. As such, it can be posited that the low privacy risk of these platforms affords them a more user-friendly design that increases the ease of use of LB-ASNS.

Based on the above findings, we posit the following hypotheses:

H3: Perceived risk will be negatively associated with (a) perceived ease of use, (b) perceived usefulness, (c) attitude toward LB-ASNS, and (d) actual use.

Finally, perceived playfulness informs us about the fulfilment of intrinsic motives (Csikszentmihalyi, 1990). Moon and Kim (2001) identified three dimensions of perceived playfulness in the context of users' interactions with the internet: (a) attention, (b) curiosity, and (c) enjoyment/interesting. Roca and Gagne (2008) demonstrated the similarity between perceived playfulness and cognitive absorption and suggested that the former can be used as the surrogate for the latter. Observe that, cognitive absorption (and by extension, its surrogate, perceived playfulness) is a state of deep immersion with a system originating from the motivation of the users' to derive intrinsic reward through the process of using the system itself. Consequently, Lowry et al. (2012) argued that this construct should be most appropriate and applicable to understand the adoption of a hedonic system. That is, perceived playfulness speaks to users' assessment of the hedonic aspects of the technology.

In the context of internet use, Agarwal and Karahanna (2000) found that cognitive absorption had a positive association with both perceived usefulness and perceived ease of use. Moon and Kim (2001) reported a positive relationship between perceived playfulness and attitude toward using the internet. Similarly, in the context of mobile social network games, perceived enjoyment was reported to have a positive association with customers' intention to adopt such applications (Park et al., 2014). As such, several studies have reported that intrinsic motivation of the users (as captured via the constructs of playfulness, joy, enjoyment) is the dominant factor determining the adoption and usage of hedonic systems (Putzke et al., 2010; Wakefiled \& Whitten, 2006). Furthermore, studies have also reported that the perception of practical usefulness of such hedonic systems is often less consequential in predicting their use (Hsu \& Lu, 2004, 2007; van der Heijden, 2003). Accordingly, we posit the following hypotheses:

H4: Perceived playfulness will be positively associated with (a) perceived ease of use, (b) perceived usefulness, (c) attitude toward LB-ASNS, and (d) actual use.

As discussed above, in addition to perceptions of the technology, perceived self-efficacy and subjective norm are also considered. Originally, perceived self-efficacy-a facet of perceived behavioral control-and subjective norm were included as antecedent variables in the theory of planned behavior (Ajzen, 1991; Fishbein \& Cappella, 2006). However, multiple studies have used these variables as antecedents to the core motivational constructs of TAM (Agudo-Peregrina et al., 2014; Ariff et al., 2012; Lee, Hsieh, \& Chen, 2013).

Perceived self-efficacy refers to an individuals' belief they have the ability to perform the desired behavior (Bandura, 1986). In an online setting, perceived self-efficacy focuses on the judgement of one's capability of finding specific information in the corresponding platform (Eastin \& LaRose, 2000). Internet self-efficacy has been reported to be a significant predictor of perceived ease of use in the context of online shopping (Eastin, 2002), e-learning (Roca, Chiu, \& Martínez, 2006), and internet phone service (Park, 2010). Additionally, perceived self-efficacy was found to have a strong positive association with perceived usefulness in the context of computer usage (Compeau \& Higgins, 1995) and adoption of e-portfolios (Abdullah, Ward \& Ahmed, 2016). In the context of computer assisted education, a positive relationship between perceived self-efficacy and attitude was reported by in Arslan (2008), and Kutluca and Ekici (2010). However, a recent meta-analysis investigating pairwise correlations among TAM constructs and several antecedent variables did not convey any information regarding the association between perceived self-efficacy and actual use of a technology (Tao et al., 2020).

In the context of LB-ASNS, perceived self-efficacy refers to the confidence of using LB-ASNS successfully to communicate anonymously with other users in the same local message board. Based on the above findings, we posit the following hypotheses: 
H5: Perceived self-efficacy will be positively associated with (a) perceived ease of use, (b) perceived usefulness, and (c) attitude toward LB-ASNS.

Lastly, subjective norm refers to the degree to which users feel pressure from their peers, directly or indirectly, to perform a particular behavior (Fishbein \& Ajzen, 1975). In an educational context, Teo, Lee, and Chai (2008) found a significant positive association between subjective norm and pre-service teachers' attitude towards adopting computers in their teaching practices. In the foregoing meta-analysis of research on TAM, Tao et al. (2020) reported an overall significant association between subjective norm and both perceived usefulness and perceived ease of use, however, they did not reveal the relationship between subjective norm and actual use of a technology. Furthermore, Gerhart and Koohikamali (2019) reported that social norms can predict intention of young adults to migrate from traditional SNS to ASNS. Note that, in all the above studies, social norm was used to predict behavioral intention and not actual use. As such, Tao et al.'s (2020) meta-analysis of TAM literature did not reveal significant relationship between subjective norm and actual use of a technology. Hence, we posit the following hypotheses:

H6: Subjective norm will be positively associated with (a) perceived ease of use, (b) perceived usefulness, and (c) attitude toward LB-ASNS.

In addition to the expected relationships between socio-technological factors and the motivational constructs as well as actual use, we also examine the relationships among the motivational constructs and actual use in the context of LB-ASNS.

Attributes of new technology, such as relative advantage and complexity, are critical to the attitude an individual forms about any new technology (Rogers, 1995). First, several TAM related studies reported that perceived ease of use had a positive relationship to perceived usefulness (Davis, 1989; Davis et al., 1989; Mathieson, 1991; Moon \& Kim, 2001; Taylor \& Todd, 1995a, 1995b; Venkatesh \& Davis, 2000). Second, both perceived usefulness and perceived ease of use shape attitudes toward the technology as well as adoption of the technology. Porter and Donthu (2006) observed positive relationships of both perceived ease of use and perceived usefulness with attitude in the context of internet usage, and Ngai, Poon, and Chan (2007) observed positive relationships of these two variables with actual use in the context of web course tools.

In our context, perceived usefulness captures the perception of external need/benefits that can be fulfilled by the information system under consideration.

Based on these findings, we posit the following hypotheses:

H7: Perceived ease of use will be positively associated with (a) perceived usefulness, (b) attitude toward LB-ASNS, and (c) actual use.

H8: Perceived usefulness will be positively associated with (a) attitude toward LB-ASNS and (b) actual use.

Finally, according to TAM, attitude toward the technology contributes to actual use. Indeed, this factor is the most important contributing factor to adoption and use of technology (Rogers, 1995). Accordingly, we posit the following hypothesis:

H9: Attitude toward LB-ASNS will be positively associated with actual use.

Based on the specific direct relationships hypothesized here, we also examine the specific indirect relationships between each of the socio-technological antecedent variables and actual use of LB-ASNS. While we expect both direct and indirect relationships between perceptions of technology and actual use of LBASNS, we expect only indirect relationships between both perceived self-efficacy and subject norm and actual use.

\section{Testing the Model on Yik Yak}

The hypothesized model (Figure 1) was examined in the context of Yik Yak, an LB-ASNS that was launched in 2013 primarily targeting U.S. college students as its user base. Superficially, Yik Yak offered anonymity to its users in the sense that one needed only a verifiable phone number/ IP address, an android/iOS operating system, and an internet connection to download this app. No further identifying information was required. Although the IP addresses were traceable, they remained confidential and hidden from other users, thereby providing technical anonymity to "Yakers." 
In 2014, Yik Yak recorded higher downloads in the AppStore as compared to Facebook or Twitter, making it one of the top 10 most-downloaded apps that year (Caya, 2019; Graham, 2017). However, with its popularity, came a slew of controversies originating from several anecdotal instances of cyberbullying, harassment, and hate speech (Mahler, 2015). To tackle this issue, Yik Yak initially relied on its Yakarma functionality that enabled users to "downvote" messages out of the feed. However, this passive moderation policy was not sufficient, and the platform eventually required its users to have an identifiable handle (Caya, 2019). This, of course, countered the promise of anonymity that was the initial selling point of this platform, and the interest in the platform started to wane (Graham, 2017). Thus, a few, but high profile, controversies, negative public perception, and gradually declining usage eventually forced Yik Yak to shut down in 2017 (Juetten, 2018).

Yik Yak thus exemplifies a case in which a promising LB-ASNS, that had the potential to cater to the utilitarian and hedonic demands of its users, fell victim to the abuse of its anonymity functionality. We therefore focus on Yik Yak to broaden our understanding of the adoption and continued use of LB-ASNS.

\section{METHOD}

\section{Data}

Data came from an online survey of students at a large southwestern public university between April 15 and May 11, 2016. Students registered with an undergraduate research participant pool (SONA study system) were invited to take this survey in exchange for course credit. The study was approved by the institutional review board at the foregoing university.

The sample comprised individuals who use (or ever had used) Yik Yak. To identify Yik Yak users, screening questions were included at the beginning of the survey. The first question asked whether the participant had used Yik Yak, and the second question asked whether an email address, phone number, or both were required to access Yik Yak. Participants who answered affirmative to the first question and correctly identified that an email address was needed to access Yik Yak were invited to complete the survey. A total of 432 Yik Yak users participated in the survey. Nine respondents did not complete the entire questionnaire and were removed from further consideration yielding a final sample size of 423 . Among these participants, the average age was 21.5 years $(S D=1.93), 28 \%$ were male, and $74 \%$ were white.

\section{Measures}

Actual use of $\angle B$-ASNS ( $\mathrm{a}=.807, \mathrm{M}=2.135, \mathrm{SD}=1.053$ ) was measured using three items, adapted from Moon and Kim (2001), that captured frequency and duration of use. The first item captured the general frequency of use of Yik Yak. It ranged from "very infrequently" (1) to "very frequently" (7). The second item measured the number of times Yik Yak was used in a typical week and ranged from "not at all" (1) to "several times each day" (7). Finally, duration measured the amount of time spent on Yik Yak and ranged from "less than 1 hour/week" (1) to "more than 25 hours/week" (7).

All predictor variables, including the exogenous and endogenous variables, were measured on a Likert scale ranging from Strongly disagree (1) to Strongly agree (7). Composite measures were created by averaging the response scores to each of the individual items.

Perceived technology affordance ( $\alpha=.746, \mathrm{M}=4.545, \mathrm{SD}=0.973$ ) was measured using six items (e.g., "Yik Yak provides opportunities for people to generate content they want to share" and "Yik Yak provides opportunities allow you to write your own opinion about what others say") adapted from Chung et al. (2010).

Perceived quality ( $\alpha=.838, M=4.295, S D=1.240$ ) was measured using three items (e.g., "Yik Yak is well designed" and "The overall quality of Yik Yak is high") adapted from Chung et al. (2010).

Perceived risk ( $\alpha=.801, M=3.834, S D=1.57$ ) was measured using three items (e.g., "I believe privacy of location based social networking app users is protected" and "I believe personal information stored on the Yik Yak is safe") adapted from Chung et al. (2010).

Perceived playfulness ( $\mathrm{a}=0.869, \mathrm{M}=3.712, \mathrm{SD}=1.112$ ) was measured using eight items (e.g., "When interacting on Yik Yak, I do not realize the time elapsed" and "Using Yik Yak gives enjoyment to me for my task") adapted from Moon and Kim (2001) to assess the strength of one's belief that interacting with Yik Yak will provide enjoyment, generate interest, curiosity and cognitive absorption. 
Perceived self-efficacy ( $\alpha=.887, M=4.112, \mathrm{SD}=1.291$ ) was measured using five items (e.g., "I feel confident in navigating Yik Yak" and "I feel confident in posting messages on Yik Yak") adapted from the General Internet Self-efficacy questionnaire (Hsu \& Chiu, 2004).

Subjective norm ( $a=.0903, M=3.074, S D=1.376$ ) was measured using three items (e.g., "My colleagues think that I should be active on Yik Yak" and "My friends think that I should actively be involved on Yik Yak") adapted from Hsu and Lu (2004).

Perceived ease of use ( $\alpha=.881, M=5.241, S D=1.118)$ was measured using three items (e.g., "It is simple to navigate the app and look at the posted messages" and "Finding my way around Yik Yak is not difficult") adapted from Chung et al. (2010).

Perceived usefulness ( $\alpha=.843, M=4.838, S D=1.388$ ) was measured using seven items (e.g., "Yik Yak is useful for Information acquisition" and "Yik Yak is useful for social support") adapted from Chung et al. (2010).

Control variables. Participants' age, gender, and race were included as control variables in the model.

\section{RESULTS}

Path analysis using maximum likelihood estimation was conducted in Mplus to examine the hypothesized model (Figure 1). Each path was controlled for the demographic variables described above.

\section{Model Fit}

The chi-square test of exact fit $\left(\chi^{2}(2)=3.516, p=0.1724\right)$ as well as measures of approximate fit (RMSEA = $0.042, \mathrm{CFI}=0.997, \mathrm{TLI}=0.941)$ indicated the adequacy of the hypothesized model.

\section{Results of the Direct Paths}

Our hypothesized model explained about $26 \%$ of the variance in actual use, $30.7 \%$ of the variance in attitude toward the LB-ASNS, $32.5 \%$ of the variance in perceived usefulness, and $26.4 \%$ of the variance in perceived ease of use.

Turning to the estimated path coefficients for the direct paths shown in Table 1, perceived technology affordance $(\gamma=0.177, p=0.001)$, perceived quality $(\gamma=0.221, p<0.001)$, perceived playfulness $(\gamma=0.08, p=$ $0.0107)$, and perceived self-efficacy $(\gamma=0.168, p=0.001)$ were positively associated with perceived ease of use. However, contrary to expectations, perceived risk was not associated with perceived ease of use, and subjective norm was negatively associated with this outcome $(\gamma=-0.23, p<0.001)$.

Perceived quality $(\gamma=0.121, p=0.022)$, perceived playfulness $(\gamma=0.279, p<0.001)$, perceived self-efficacy $(\gamma=0.124, p=0.015)$, and subjective norm $(\gamma=0.193, p<0.001)$ were positively associated with perceived usefulness. However, contrary to expectations, perceived technology affordance and perceived risk were not associated with perceived usefulness, and perceived ease of use was negatively associated with this outcome $(\beta=-0.202, p<0.001)$.

Perceived quality $(\gamma=0.156, p=0.003)$, subjective norm $(\gamma=0.68, p=0.001)$, and perceived usefulness $(\gamma=$ $0.141, p=0.004$ ) were positively associated with attitude toward LB-ASNS. However, contrary to expectations, perceived technology affordance, perceived risk, perceived playfulness, and perceived self-efficacy were not associated with attitude toward LB-ASNS.

Finally, perceived quality $(\gamma=0.128, p=0.020)$, perceived playfulness $(\gamma=0.252, p<0.001)$, and attitude toward LB-ASNS ( $\beta=0.241, p<0.001$ ) were positively associated with actual use of LB-ASNS. However, contrary to expectations, perceived technology affordance was negatively associated with actual use $(\gamma=-0.135, p=$ 0.010), and perceived risk, perceived ease of use, and perceived usefulness were not associated with this outcome. 
Table 1. Maximum likelihood estimates and significance level on standardized direct path coefficients

\begin{tabular}{|c|c|c|c|}
\hline Path & Standardized Estimate & Significance & Support for hypothesis \\
\hline \multicolumn{4}{|l|}{ Perceived ease of use on } \\
\hline Perceived technology affordance & 0.177 & 0.001 & H1a: supported \\
\hline Perceived quality & 0.221 & $<0.001$ & H2a: supported \\
\hline Perceived risk & 0.088 & 0.067 & H3a: not supported \\
\hline Perceived playfulness & 0.080 & 0.0107 & H4a: supported \\
\hline Perceived self-efficacy & 0.168 & 0.001 & H5a: supported \\
\hline Subjective norm & -0.230 & $<0.001$ & H6a: not supported \\
\hline \multicolumn{4}{|l|}{ Perceived usefulness on } \\
\hline Perceived technology affordance & 0.056 & 0.267 & H1b: not supported \\
\hline Perceived quality & 0.121 & 0.022 & H2b: supported \\
\hline Perceived risk & -0.004 & 0.930 & H3b: not supported \\
\hline Perceived playfulness & 0.279 & $<0.001$ & H4b: supported \\
\hline Perceived self-efficacy & 0.124 & 0.015 & H5b: supported \\
\hline Subjective norm & 0.193 & $<0.001$ & H6b: supported \\
\hline Perceived ease of use & -0.202 & $<0.001$ & H7a: not supported \\
\hline \multicolumn{4}{|l|}{ Attitude on } \\
\hline Perceived technology affordance & 0.063 & 0.220 & H1c: not supported \\
\hline Perceived quality & 0.156 & 0.003 & H2c: supported \\
\hline Perceived risk & 0.078 & 0.095 & H3c: not supported \\
\hline Perceived playfulness & 0.033 & 0.510 & H4c: not supported \\
\hline Perceived self-efficacy & 0.099 & 0.057 & H5c: not supported \\
\hline Subjective norm & 0.168 & 0.001 & H6c: supported \\
\hline Perceived ease of use & 0.069 & 0.151 & H7b: not supported \\
\hline Perceived usefulness & 0.141 & 0.004 & H8a: supported \\
\hline \multicolumn{4}{|l|}{ Actual Use on } \\
\hline Perceived technology affordance & -0.135 & 0.010 & H1d: not supported \\
\hline Perceived quality & 0.128 & 0.020 & H2d: supported \\
\hline Perceived risk & -0.044 & 0.345 & H3d: not supported \\
\hline Perceived playfulness & 0.252 & $<0.001$ & H4d: supported \\
\hline Perceived ease of use & 0.048 & 0.325 & H7c: not supported \\
\hline Perceived usefulness & 0.036 & 0.471 & H8b: not supported \\
\hline Attitude & 0.241 & $<0.001$ & H9: supported \\
\hline
\end{tabular}

Note: All paths control for demographics variables (age, gender, and race)

\section{Results of the Indirect Paths}

Turning to the estimated path coefficients for the indirect paths, in addition to the direct association between perceived quality and actual use, there was also an indirect association between these two variables. Specifically, perceived quality was associated with actual use through its association with attitude toward LB$\operatorname{ASNS}(\gamma=0.038, p=0.012)$. Also, in addition the direct association between perceived playfulness and actual use, there was also an indirect association between these two variables. Specifically, perceived playfulness was associated with actual use through its association with perceived usefulness and in turn attitude toward LB-ASNS $(\gamma=0.010, p=0.022)$. Moreover, there was an indirect association between subjective norm and actual use. Specifically, subject norm was associated with actual use through (1) attitude toward LB-ASNS $(\gamma=$ $0.040, p=0.005)$, (2) perceived usefulness and in turn attitude toward LB-ASNS $(\gamma=0.007, p=0.034)$, and (3) perceived ease of use and in turn perceived usefulness and attitude toward LB-ASNS $(\gamma=0.002, p=0.049)$. However, there were no indirect associations between perceived technology affordance, perceived risk, or perceived self-efficacy and actual use.

\section{DISCUSSION}

This study proposed that TAM, and its extensions, is useful in understanding adoption behavior of LBASNS from a utilitarian and hedonic perspective. Results showed that the model provided good fit, although not all hypothesized paths were significant. With regard to the antecedent variables, results showed that among the perceptions of technology, only perceived quality and perceived playfulness predicted actual use 
of LB-ASNS, and their relationships to actual use were both direct and indirect (through attitude in the case of perceived quality and through perceived usefulness and attitude in the case of perceived playfulness). Moreover, perceived playfulness emerged as the strongest predictor of actual use. Results also showed that among perceived self-efficacy and subjective norm, only subjective norm predicted actual use of LB-ASNS, and its relationship to actual use was only indirect (through perceived ease of use, perceived usefulness, and attitude toward LB-ASNS; perceived usefulness and attitude; and attitude). However, perceived risk, perceived technology affordance, and perceived usefulness were not significant predictors of actual use of LB-ASNS.

With regard to the motivational constructs, results showed that only attitude toward LB-ASNS predicted actual use of LB-ASNS. While perceived ease of use predicted perceived usefulness, their relationship to actual use of LB-ASNS appeared to be fully mediated through attitude toward LB-ASNS. This finding corroborated the assertion that when adoption is voluntary, the actual of technology is primarily determined by users' attitude towards the said technology (Kapoor et al., 2014).

For college students, the inclusivity afforded by the LB-ASNS allows new students to be a part of aggregated communication about the locality that echoed the temporal rhythm of the physical space. We captured this phenomenon via subjective norm which is often related to the development of a community (Koohikamali, Gerhart, \& Mousavizadeh, 2015). Not surprisingly, subjective norm turned out to be a significant predictor for both perceived usefulness and attitude toward Yik Yak and had significant indirect effect on the actual use of this platform. Thus, our finding offers empirical support to the qualitative results reported in Vaterlaus (2017). However, perceived risk did not play any significant role in predicting any of the TAM constructs, although that feature of LB-ASNS has been used as a marketing tactic (Graham, 2015).

Taken together, the results of this study suggest that use of LB-ASNS, like Yik Yak, is not based on users' perceptions of what the technology can do for them in terms of generating content, the risks involved in doing so, or their belief in their ability to use the technology. This is not particularly surprising given its basic affordances, provision of anonymity, and user-friendly design. Instead, it appears that use of LB-ASNS is based more on users' perceptions of quality, enjoyment, and whether they perceive that their friends and acquaintances support their use of these platforms. That is, the perceived hedonic and social value of the platform may be more important than its perceived utilitarian value. These results lend additional support to the findings of Al-Qaysi, Mohamad-Nordin, and Al-Emran (2020) who found that perceived enjoyment and subjective norm were the top two predictors of the usage of the social media. It appears that users adopt LBASNS simply to engage in informal communication with individuals belonging to a community for the pleasure and enjoyment it brings. The users potentially find common ground in sharing similar experiences that the temporal rhythm of their shared physical space exposes them to (Frith \& Saker, 2017).

\section{Implications}

These findings offer some important theoretical as well as practical implications. Regarding the theoretical implications, although we suggested that LB-ASNS likely serves a dual function, satisfying both utilitarian and hedonic needs, the findings suggest that such technology should be examined purely from a hedonic systems approach. In particular, when considering the relationship between perceived usefulness and actual use of LB-ASNS, perceived usefulness must be conceptualized as usefulness expected from a predominantly hedonic system. This conceptualization was utilized in Lowry et al. (2012), where they contextualized perceived usefulness as "useful for having fun, relaxing" (p. 620) a-priori.

Regarding the practical implications for developers of LB-ASNS, these findings offer some circumstantial evidence that needs to be explicated properly in order to understand the adoption and predict the continued usage of this special class of SNS. First, we find that the anonymity construct turns out be inconsequential in predicting the actual use of the platform. However, users' interest in Yik Yak waned rapidly when the platform, in order to combat toxic disinhibition engendered by anonymity, required its users to create a handle (Graham, 2017). Thus, it can be conjectured that while anonymity is an attractive feature of LB-ASNS, it has little effect on the frequency and continued usage of such platform. Gerhart and Koohikamali (2019) also reported that anonymity did not play a significant role in users' intention to migrate to an anonymous social networking platforms. Consequently, it appears that LB-ASNS must offer more functionalities to induce higher user engagement. 
What other functionalities can LB-ASNS offer? We find that users reported to derive enjoyment from using Yik Yak and that this intrinsic motivation turns out to be the dominant predictor for actual use of this platform. Consequently, we posit that features enhancing the perceived playfulness of these platforms can increase the frequency of their usage and induce user loyalty.

Finally, despite the fact that perceived risk did not turn out to be an important predictor, the role of anonymity in adoption and usage of LB-ASNS needs to be examined very carefully. On one hand, anonymity is one of the defining characteristics of LB-ASNS. Compromising this feature may have a strong negative impact on the success of these platforms (Machkovech, 2016). Regardless, there exists incontrovertible evidence that the anonymity afforded by LB-ASNS (and, in general, ASNS) has been abused. Such abuse creates conditions that result in cyberbullying, doxing, and other manifestations of toxic disinhibitions. Such content may even jeopardize the survival of the platform. As the case in point, Yik Yak's inability to adequately balance the anonymity aspect while addressing the controversial and inflammatory contents in this platform resulted in its downfall. Therefore, it appears that, in order to survive, LB-ASNS must continue to afford anonymity and allow for playfulness, but in a safe and comfortable environment. One option that these platforms must consider is development of robust, transparent, and, perhaps, site-specific content moderation strategies that do not conflict with the hedonic aspects of these platforms (Machkovech, 2016). Although, discussion on such e-safety protocols is beyond the scope of this article, we simply observe that the now-defunct Yik Yak largely relied on the in-built self-regulating mechanism of up/downvoting to winnow out toxic content, thereby democratizing a large part of the content moderation policy (Milosevic, 2016). On the other hand, Whisper - an older and still popular LB-ASNS - uses a combination of their proprietary machine learning algorithm and a team of well-trained human moderators to determine what content to post on this platform and what to ban (O'Brien, 2015; Ortutay, 2014).

\section{Limitations and Future Directions}

Although our findings reveal some important insights regarding the adoption and use of LB-ASNS, some caution needs to be exercised in drawing widely generalizable conclusions. First, the sample comprised of a convenience sample as opposed to a probability sample. However, that limitation is partially offset by focusing on the population of college students, who are the principal target audience for LB-ASNS. Indeed, the rising popularity of ASNS is mostly observed on U.S. college campuses (Burns, 2014). Also, the non-experimental and cross-sectional nature of this study prohibits any conclusion about temporality and hence the causal influence of the socio-technological constructs on the motivational constructs and actual use of LB-ASNS cannot be ascertained. Lastly, when this study was conducted, Yik Yak was very popular among U.S. college students. However, the app was shut down within one year of this study indicating a potential change in the perception of the audience of this app. Consequently, caution needs to be exercised to temporally extrapolate the results from this study.

Regardless of these limitations, our findings can be used to understand the relationships among the core TAM constructs and actual use of LB-ASNS. We demonstrated that an extended version of TAM could be successfully utilized to explain adoption and use of LB-ASNS. We also demonstrated that the hedonic aspects of LB-ASNS were more relevant to the actual use of these platforms as compared to their anonymity and utilitarian aspects. Consequently, the findings of our study can be utilized to explain the adoption of currently popular LB-ASNS, for example, Whisper and Anomo. The general agreement between our findings and those reviewed at the outset of our study that applied TAM in the context of non-anonymous social media (Al-Qaysi, Mohamad-Nordin, \& Al-Emran, 2020) indicates that there exists a potential set of common socio-technological constructs that can predict the adoption behavior of a general class of SNS, anonymous or otherwise. Uncovering these common factors is a promising avenue of future research.

Future studies should focus on validating our results through the use of an experiment. This would also provide a unique opportunity to examine the use of different content moderation strategies that does not infringe upon users' freedom of expression and does not conflict with the hedonic aspects of LB-ASNS. As discussed in the implications, the long-term success of LB-ASNS may depend on this.

Author contributions: All authors were involved in concept, design, collection of data, interpretation, writing, and critically revising the article. All authors approve final version of the article.

Funding: The authors received no financial support for the research and/or authorship of this article. 
Declaration of interest: Authors declare no competing interest.

Data availability: Data generated or analysed during this study are available from the authors on request.

\section{REFERENCES}

Abdullah, F., Ward, R., \& Ahmed, E. (2016). Investigating the influence of the most commonly used external variables of TAM on students' Perceived Ease of Use (PEOU) and Perceived Usefulness (PU) of eportfolios. Computers in Human Behavior, 63, 75-90. https://doi.org/10.1016/j.chb.2016.05.014

Aboelmaged, M., \& Gebba, T. R. (2013). Mobile banking adoption: an examination of technology acceptance model and theory of planned behavior. International Journal of Business Research and Development, 2(1), 35-50. https://doi.org/10.24102/ijbrd.v2i1.263

Agarwal, R., \& Karahanna, E. (2000). Time flies when you're having fun: Cognitive absorption and beliefs about information technology usage. MIS Quarterly, 665-694. https://doi.org/10.2307/3250951

Agudo-Peregrina, Á. F., Hernández-García, Á., \& Pascual-Miguel, F. J. (2014). Behavioral intention, use behavior and the acceptance of electronic learning systems: Differences between higher education and lifelong learning. Computers in Human Behavior, 34, 301-314. https://doi.org/10.1016/j.chb.2013.10.035

Ajzen, I. (1991). The theory of planned behavior. Organizational Behavior and Human Decision Processes, 50(2), 179-211. https://doi.org/10.1016/0749-5978(91)90020-T

Al-Qaysi, N., Mohamad-Nordin, N., \& Al-Emran, M. (2020). Employing the technology acceptance model in social media: A systematic review. Education and Information Technologies, 25, 4961-5002. https://doi.org/10.1007/s10639-020-10197-1

Ariff, M. S. M., Yeow, S. M., Zakuan, N., Jusoh, A., \& Bahari, A. Z. (2012). The effects of computer self-efficacy and technology acceptance model on behavioral intention in internet banking systems. Procedia-Social and Behavioral Sciences, 57, 448-452. https://doi.org/10.1016/j.sbspro.2012.09.1210

Arslan, A. (2008). The correlation between attitude and self-efficacy with regard to computer assisted education. Electronic Journal of Social Sciences, 7(24), 101-109. https://dergipark.org.tr/esosder/issue/6138/82343

Ayyagari, R., Grover, V., \& Purvis, R. (2011). Technostress: technological antecedents and implications. MIS quarterly, 831-858. https://doi.org/10.2307/41409963

Bandura, A. (1986). Social foundations of thought and action: A social cognitive theory. Prentice-Hall, Inc.

Bauer, R. A. (1960). Consumer behavior as risk taking. In R. S. Hancock (Ed.), Dynamic Marketing for a Changing World, Proceedings of the 43rd Conference of the American Marketing Association, pp. 389-98.

Benbasat, I., \& Barki, H. (2007). Quo vadis TAM?. Journal of the Association for Information Systems, 8(4), 7. https://doi.org/10.17705/1jais.00126

Biucky, S. T., \& Harandi, S. R. (2017). The effects of perceived risk on social commerce adoption based on tam model. International Journal of Electronic Commerce Studies, 8(2), 173-196. https://doi.org/10.7903/ijecs. 1538

Black, E. W., Mezzina, K., \& Thompson, L. A. (2016). Anonymous social media-Understanding the content and context of Yik Yak. Computers in Human Behavior, 57, 17-22. https://doi.org/10.1016/j.chb.2015.11.043

Boyd, D., \& Marwick, A. E. (2011, September). Social privacy in networked publics: Teens' attitudes, practices, and strategies. In A decade in internet time: Symposium on the dynamics of the internet and society, pp. 129. https://papers.ssrn.com/sol3/papers.cfm?abstract_=1925128

Bradner, E. (2001, March). Social affordances of computer-mediated communication technology: understanding adoption. In CHI'01 Extended abstracts on human factors in computing systems (pp. 67-68). https://doi.org/10.1145/634067.634111

Burns, H. (2014). Yik Yak app stirring up chatter on college campuse. https://www.usatoday.com/story/tech/ personal/2014/03/07/yik-yak-college-students/6124405/

Caya. (2019) Company forensics | Yik Yak: A deadly combination. https://slidebean.com/blog/startups-startupforensics-yik-yak

Chen, C. C., \& Tsai, J. L. (2019). Determinants of behavioral intention to use the Personalized Location-based Mobile Tourism Application: An empirical study by integrating TAM with ISSM. Future Generation Computer Systems, 96, 628-638. https://doi.org/10.1016/j.future.2017.02.028 
Chen, D. X. (2004). Students' sense of campus community: What it means, and what to do about it. NASPA Journal, 41, 216-234. https://doi.org/10.2202/1949-6605.1331

Choi, T. R., \& Sung, Y. (2018). Instagram versus Snapchat: Self-expression and privacy concern on social media. Telematics and Informatics, 35(8), 2289-2298. https://doi.org/10.1016/j.tele.2018.09.009

Chung, J. E., Park, N., Wang, H., Fulk, J., \& McLaughlin, M. (2010). Age differences in perceptions of online community participation among non-users: An extension of the Technology Acceptance Model. Computers in Human Behavior, 26(6), 1674-1684. https://doi.org/10.1016/j.chb.2010.06.016

Clark-Gordon, C. V., Bowman, N. D., Goodboy, A. K., \& Wright, A. (2019). Anonymity and Online Self-Disclosure: A Meta-Analysis. Communication Reports, 32(2), 98-111. https://doi.org/10.1080/08934215.2019.1607516

Clark-Gordon, C. V., Workman, K. E., \& Linvill, D. L. (2017). College students and Yik Yak: An exploratory mixedmethods study. Social Media+ Society, 3(2), 2056305117715696. https://doi.org/10.1177/205630511 7715696

Compeau, D. R., \& Higgins, C. A. (1995). Application of social cognitive theory to training for computer skills. Information systems research, 6(2), 118-143. https://doi.org/10.1287/isre.6.2.118

Csikszentmihalyi, M. (1990). Flow: The psychology of optimal experience. Harper \& Row.

Currás-Pérez, R., Ruiz-Mafé, C., \& Sanz-Blas, S. (2013). Social network loyalty: evaluating the role of attitude, perceived risk and satisfaction. Online Information Review, 37(1), 61-82. https://doi.org/10.1108/ 14684521311311630

Davis, F. D. (1989). Perceived usefulness, perceived ease of use, and user acceptance of information technology. MIS quarterly, 319-340. https://doi.org/10.2307/249008

Davis, F. D., Bagozzi, R. P., \& Warshaw, P. R. (1989). User acceptance of computer technology: a comparison of two theoretical models. Management science, 35(8), 982-1003. https://doi.org/10.1287/mnsc.35.8.982

de la Fuente, J., Gustafson, S., Twomey, C., \& Bix, L. (2015). An affordance-based methodology for package design. Packaging Technology and Science, 28(2), 157-171. https://doi.org/10.1002/pts.2087

DeLone, W. H., \& McLean, E. R. (1992). Information systems success: The quest for the dependent variable. Information systems research, 3(1), 60-95. https://doi.org/10.1287/isre.3.1.60

Eastin, M. S. (2002). Diffusion of e-commerce: an analysis of the adoption of four e-commerce activities. Telematics and informatics, 19(3), 251-267. https://doi.org/10.1016/S0736-5853(01)00005-3

Eastin, M. S., \& LaRose, R. (2000). Internet self-efficacy and the psychology of the digital divide. Journal of computer-mediated communication, 6(1), JCMC611. https://doi.org/10.1111/j.1083-6101.2000.tb00110.x

Fishbein, M., \& Ajzen, I. (1975). Belief, attitude, intention and behavior: An introduction to theory and research. Addison-Wesley.

Fishbein, M., \& Cappella, J. N. (2006). The role of theory in developing effective health communications. Journal of Communication, 56(s1), S1-S17. https://doi.org/10.1111/j.1460-2466.2006.00280.x

Frith, J., \& Saker, M. (2017). Understanding Yik Yak: Location-based sociability and the communication of place. First Monday, 22(10). https://doi.org/10.5210/fm.v22i10.7442

Galib, M. H., Hammou, K. A., \& Steiger, J. (2018). Predicting consumer behavior: an extension of technology acceptance model. International Journal of Marketing Studies, 10(3), 73-90. https://doi.org/10.5539/ijms.v10n3p73

Gefen, D., Karahanna, E., \& Straub, D. W. (2003). Trust and TAM in online shopping: An integrated model. MIS quarterly, 27(1), 51-90. https://doi.org/10.2307/30036519

Gerhart, N., \& Koohikamali, M. (2019). Social network migration and anonymity expectations: What anonymous social network apps offer. Computers in Human Behavior, 95, 101-113. https://doi.org/10.1016/j.chb.2019.01.030

Gibson, J. J. (1979). The ecological approach to visual perception. Houghton Mifflin.

Golbeck, J., \& Mauriello, M. L. (2016). User perception of Facebook app data access: A comparison of methods and privacy concerns. Future Internet, 8(2), 9. https://doi.org/10.3390/fi8020009

Goodhue, D. L. (2007). Comment on Benbasat and Barki's "Quo Vadis TAM" article. Journal of the Association for Information Systems, 8(4), 15. https://doi.org/10.17705/1jais.00125

Govender, I., \& Sihlali, W. (2014). A study of mobile banking adoption among university students using an extended TAM. Mediterranean Journal of Social Sciences, 5(7), 451. https://doi.org/10.5901/ mjss.2014.v5n7p451 
Graham, J. (2015) Anonymity working for Whisper app. https://www.usatoday.com/story/tech/2015/08/12/ anonymity-working-whisper-app-secret-snapchat/31514503/

Graham, J. (2017) Yik Yak, the once popular and controversial college messaging app, shuts down. https://www.usatoday.com/story/tech/talkingtech/2017/04/28/yik-yak-shut-down/101045670/

Gumussoy, C. A., Kaya, A., \& Ozlu, E. (2018). Determinants of mobile banking use: An extended TAM with perceived risk, mobility access, compatibility, perceived self-efficacy and subjective norms. In Industrial Engineering in the Industry 4.0 Era (pp. 225-238). Springer, Cham. https://doi.org/10.1007/978-3-31971225-3_20

Hall, J. (2013) Hannah Smith suicide: Internet trolls target sister of tragic teenager who was driven to suicide by cyberbullies. https://www.independent.co.uk/news/uk/crime/hannah-smith-suicide-internet-trollstarget-sister-tragic-teenager-who-was-was-driven-suicide-cyberbullies-8749648.html

Hsu, C. L. \& Lu, H. P. (2007). Consumer behavior in online game communities: A motivational factor perspective. Computers in Human Behavior, 23(3), 1642-1659. https://doi.org/10.1016/j.chb.2005.09.001

Hsu, C. L., \& Lu, H. P. (2004). Why do people play on-line games? An extended TAM with social influences and flow experience. Information \& management, 41(7), 853-868. https://doi.org/10.1016/j.im.2003.08.014

Hsu, M. H., \& Chiu, C. M. (2004). Internet self-efficacy and electronic service acceptance. Decision support systems, 38(3), 369-381. https://doi.org/10.1016/j.dss.2003.08.001

Juetten, M. (Nov, 13, 2018). Failed Startups: YikYak. https://www.forbes.com/sites/maryjuetten/2018/11/13/ failed-startups-yik-yak/

Kamble, S., Gunasekaran, A., \& Arha, H. (2019). Understanding the Blockchain technology adoption in supply chains-Indian context. International Journal of Production Research, 57(7), 2009-2033. https://doi.org/10.1080/00207543.2018.1518610

Kapoor, K., Dwivedi, Y., Piercy, N. C., Lal, B., \& Weerakkody, V. (2014). RFID integrated systems in libraries: extending TAM model for empirically examining the use. Journal of Enterprise Information Management, 27(6), 731-758. https://doi.org/10.1108/JEIM-10-2013-0079

Koohikamali, M., Gerhart, N., \& Mousavizadeh, M. (2015). Location disclosure on LB-SNAs: The role of incentives on sharing behavior. Decision Support Systems, 71, 78-87. https://doi.org/10.1016/j.dss.2015. 01.008

Kutluca, T., \& Ekici, G. (2010). Examining teacher candidates' attitudes and self-effıcacy perceptions towards the computer assisted education. Hacettepe University Journal of Education, 38, 177-188. http://www.efdergi.hacettepe.edu.tr/shw_artcl-426.html

LaRose, R., \& Atkin, D. (1991). Attributes of movie distribution channels and consumer choice. Journal of Media Economics, 4(1), 3-17. https://doi.org/10.1080/08997769109358200

Lauri, M. A., \& Farrugia, L. (2020). Identity Exploration in Anonymous Online Spaces. The Routledge Companion to Digital Media and Children, 173-184. https://doi.org/10.4324/9781351004107-16

Lee, Y. H., Hsieh, Y. C., \& Chen, Y. H. (2013). An investigation of employees" use of e-learning systems: applying the technology acceptance model. Behaviour \& Information Technology, 32(2), 173-189. https://doi.org/10.1080/0144929X.2011.577190

Lee, Y., Kozar, K. A., \& Larsen, K. R. (2003). The technology acceptance model: Past, present, and future. Communications of the Association for information systems, 12(1), 50. https://doi.org/10.17705/1CAIS.01250

Li, Q., \& Literat, I. (2017). Misuse or misdesign? Yik Yak on college campuses and the moral dimensions of technology design. First Monday, 22(7). https://doi.org/10.5210/fm.v22i7.6947

Lin, H.F. (2008). Antecedents of virtual community satisfaction and loyalty: An empirical test of competing theories. CyberPsychology \& Behavior, 11(2),138-144. https://doi.org/10.1089/cpb.2007.0003

Liu, X. (2010). Empirical testing of a theoretical extension of the technology acceptance model: An exploratory study of educational wikis. Communication Education, 59(1), 52-69. https://doi.org/10.1080/03634520903431745

Lorenzo-Romero, C., \& Constantinides, E. (2011). Consumer adoption of social networking sites: implications for theory and practice. Journal of research in Interactive Marketing, 5(2/3), 170-188. https://doi.org/10.1108/17505931111187794 
Lowry, P. B., Gaskin, J., Twyman, N., Hammer, B., \& Roberts, T. (2012). Taking "fun and games" seriously: Proposing the hedonic-motivation system adoption model (HMSAM). Journal of the Association for Information Systems, 14(11), 617-671. https://doi.org/10.17705/1jais.00347

Machkovech, S. (2016). Yik Yak's "handles" are just lipstick on an ugly, anonymous yak. https://arstechnica.com/ information-technology/2016/03/yik-yaks-handles-are-just-lipstick-on-an-ugly-anonymous-yak/

Madden, M., \& Rainie, L. (2015). Americans" attitudes about privacy, security and surveillance. Pew Research Center. http://www.pewinternet.org/2015/05/20/americans-attitudes-about-privacy-security-and-surveil lance/

Madden, M., Lenhart, A., Cortesi, S., Gasser, U., Duggan, M., Smith, A., \& Beaton, M. (2013). Teens, social media, and privacy. Pew Research Center, 21(1055), 2-86. https://assets.pewresearch.org/wpcontent/uploads/sites/14/2013/05/PIP_TeensSocialMediaandPrivacy_PDF.pdf

Mahler, J. (2015). Who spewed that abuse? Anonymous Yik Yak app isn"t telling. https://www.nytimes.com/ 2015/03/09/technology/popular-yik-yak-app-confers-anonymity-and-delivers-abuse.html

Majchrzak, A., Faraj, S., Kane, G. C., \& Azad, B. (2013). The contradictory influence of social media affordances on online communal knowledge sharing. Journal of Computer-Mediated Communication, 19(1), 38-55. https://doi.org/10.1111/jcc4.12030

Makki, T. W., DeCook, J. R., Kadylak, T., \& Lee, O. J. Y. (2018). The social value of snapchat: An exploration of affiliation motivation, the technology acceptance model, and relational maintenance in Snapchat use. International Journal of Human-Computer Interaction, 34(5), 410-420. https://doi.org/10.1080/10447318. 2017.1357903

Mao, C. M., \& Hovick, S. R. (2020). Adding affordances and communication efficacy to the technology acceptance model to study the messaging features of online patient portals among young adults. Health Communication, 1-9. https://doi.org/10.1080/10410236.2020.1838106

Marangunić, N., \& Granić, A. (2015). Technology acceptance model: A literature review from 1986 to 2013. Universal Access Information Society, 14, 81-95. https://doi.org/10.1007/s10209-014-0348-1

Mathieson, K. (1991). Predicting user intentions: comparing the technology acceptance model with the theory of planned behavior. Information systems research, 2(3), 173-191. https://doi.org/10.1287/isre.2.3.173

McGuire, W. J. (1969). The nature of attitudes and attitude change, In G. Lintzey \& E. Aronson (Eds.), Handbook of Social Psychology. Addison-Wesley.

Milosevic, T. (2016). Social media companies' cyberbullying policies. International Journal of Communication, 10, 5164-5185. https://ijoc.org/index.php/ijoc/article/view/5320

Moon, J.-W. \& Kim, Y.-G. (2001) Extending the TAM for a World-Wide-Web context. Information and Management, 38, 217-230. https://doi.org/10.1016/S0378-7206(00)00061-6

Moore, M. J., Nakano, T., Enomoto, A., \& Suda, T. (2012). Anonymity and roles associated with aggressive posts in an online forum. Computers in Human Behavior, 28(3), 861-867. https://doi.org/10.1016/j.chb.2011. 12.005

Murimi, R. (2018, November). Online Social Networks for Meaningful Social Reform. In 2018 World Engineering Education Forum-Global Engineering Deans Council (WEEF-GEDC) (pp. 1-6). IEEE. https://doi.org/10.1109/WEEF-GEDC.2018.8629713

Mynatt, E. D., O’Day, V. L., Adler, A., \& Ito, M. (1998). Network communities: Something old, something new, something borrowed... Computer supported Cooperative Work (CSCW), 7(1-2), 123-156. https://doi.org/10.1023/A:1008688205872

Ngai, E. W., Poon, J. K. L., \& Chan, Y. H. (2007). Empirical examination of the adoption of WebCT using TAM. Computers \& Education, 48(2), 250-267. https://doi.org/10.1016/j.compedu.2004.11.007

Norman, D. A. (1988). The design of everyday things. Doubleday.

O'Brien, S. A. (2015). 20 million people are sharing secrets on this app. https://money.cnn.com/2015/12/11/ technology/whisper-20-million-users-privacy

Ortutay, B. (2014). Anonymous apps like Secret and Whisper find a niche in Silicon Valley. https://www.mercury news.com/2014/03/24/anonymous-apps-like-secret-and-whisper-find-a-niche-in-silicon-valley/

Park, E., Baek, S., Ohm, J., \& Chang, H. J. (2014). Determinants of player acceptance of mobile social network games: An application of extended technology acceptance model. Telematics and Informatics, 31(1), 3-15. https://doi.org/10.1016/j.tele.2013.07.001 
Park, N. (2010). Adoption and use of computer-based voice over Internet protocol phone service: Toward an integrated model. Journal of Communication, 60(1), 40-72. https://doi.org/10.1111/j.1460-2466.2009. 01440.x

Pedersen, D. M. (1997). Psychological functions of privacy. Journal of environmental psychology, 17(2), 147-156. https://doi.org/10.1006/jevp.1997.0049

Peter, J., \& Valkenburg, P. M. (2011). Adolescents" online privacy: Toward a developmental perspective. In Privacy online (pp. 221-234). Springer, Berlin, Heidelberg. https://doi.org/10.1007/978-3-642-21521-6_16

Petter, S., DeLone, W., \& McLean, E. (2008). Measuring information systems success: models, dimensions, measures, and interrelationships. European journal of information systems, 17(3), 236-263. https://doi.org/10.1057/ejis.2008.15

Pinsonneault, A., \& Heppel, N. (1997). Anonymity in group support systems research: A new conceptualization, measure, and contingency framework. Journal of Management Information Systems, 14(3), 89-108. https://doi.org/10.1080/07421222.1997.11518176

Porter, C. E., \& Donthu, N. (2006). Using the technology acceptance model to explain how attitudes determine Internet usage: The role of perceived access barriers and demographics. Journal of business research, 59(9), 999-1007. https://doi.org/10.1016/j.jbusres.2006.06.003

Posteuca-Esi, N. L. (2019). Social and psychological benefits of self-disclosure. International Journal of Social and Educational Innovation (IJSEIro), 6(12), 25-29. https://www.journals.aseiacademic.org/index.php/ijsei/ article/view/136

Putzke, J., Fischbach, K., Schoder, D., \& Gloor, P. (2010). The evolution of interaction networks in massively multiplayer online games. Journal of the Association for Information Systems, 11(2), 69-94. https://doi.org/10.17705/1jais.00221

Ramírez-Correa, P., Grandón, E. E., Ramírez-Santana, M., \& Belmar Órdenes, L. (2019). Explaining the use of social network sites as seen by older adults: The enjoyment component of a hedonic information system. International journal of environmental research and public health, 16(10), 1673. https://doi.org/10.3390/ijerph16101673

Razmak, J., \& Bélanger, C. (2018). Using the technology acceptance model to predict patient attitude toward personal health records in regional communities. Information Technology \& People. https://doi.org/10.1108/ITP-07-2016-0160

Ritz, W., Wolf, M., \& McQuitty, S. (2019). Digital marketing adoption and success for small businesses. Journal of Research in Interactive Marketing. https://doi.org/10.1108/JRIM-04-2018-0062

Roca, J. C., \& Gagné, M. (2008). Understanding e-learning continuance intention in the workplace: A selfdetermination theory perspective. Computers in Human Behavior, 24(4), 1585-1604. https://doi.org/10.1016/j.chb.2007.06.001

Roca, J. C., Chiu, C. M., \& Martínez, F. J. (2006). Understanding e-learning continuance intention: An extension of the technology acceptance model. International Journal of Human-Computer Studies, 64(8), 683-696. https://doi.org/10.1016/j.ijhcs.2006.01.003

Rogers E., M. (1995). The diffusion of innovation (4th ed). Free Press.

Saker, M., \& Evans, L. (2016). Everyday life and locative play: An exploration of Foursquare and playful engagements with space and place. Media, Culture \& Society, 38(8), 1169-1183. https://doi.org/10.1177/0163443716643149

Tao, D., Wang, T., Wang, T., Zhang, T., Zhang, X., \& Qu, X. (2020). A systematic review and meta-analysis of user acceptance of consumer-oriented health information technologies. Computers in Human Behavior, 104, 106147. https://doi.org/10.1016/j.chb.2019.09.023

Tate, M., \& Evermann, J. (2009). Perceptive users with attitudes-some heuristics on theorizing. ICIS 2009 Proceedings, 139.

Taylor, S., \& Todd, P. A. (1995a). Understanding information technology usage: A test of competing models. Information Systems Research, 6, 144-176. https://doi.org/10.1287/isre.6.2.144

Taylor, S., \& Todd, P. A. (1995b). Assessing IT usage: The role of prior experience. MIS Quarterly, 19(4), 561-570. https://doi.org/10.2307/249633

Teo, T., Lee, C. B., \& Chai, C. S. (2008). Understanding pre-service teachers' computer attitudes: applying and extending the technology acceptance model. Journal of Computer Assisted Learning, 24(2), 128-143. https://doi.org/10.1111/j.1365-2729.2007.00247.x 
Tsai, T. H., Chang, H. T., \& Ho, Y. L. (2016). Perceptions of a specific family communication application among grandparents and grandchildren: An extension of the technology acceptance model. PloS one, 11(6), e0156680. https://doi.org/10.1371/journal.pone.0156680

Tsay-Vogel, M., Shanahan, J., \& Signorielli, N. (2018). Social media cultivating perceptions of privacy: A 5-year analysis of privacy attitudes and self-disclosure behaviors among Facebook users. New Media \& Society, 20(1), 141-161. https://doi.org/10.1177/1461444816660731

Valkenburg, P. M., \& Peter, J. (2011). Online communication among adolescents: An integrated model of its attraction, opportunities, and risks. Journal of Adolescent Health, 48(2), 121-127. https://doi.org/10.1016/j.jadohealth.2010.08.020

van der Heijden, H. (2003). Factors influencing the usage of websites: The case of a generic portal in The Netherlands. Information \& Management, 40(6), 541-549. https://doi.org/10.1016/S0378-7206(02)000794

Vaterlaus, J. M. (2017). Yik Yak: An exploratory study of college student uses and gratifications. Bulletin of Science, Technology \& Society, 37(1), 23-33. https://doi.org/10.1177/0270467617738902

Venkatesh, V., \& Davis, F. D. (2000). A theoretical extension of the technology acceptance model: Four longitudinal field studies. Management Science, 46(2), 186-204. https://doi.org/10.1287/mnsc.46.2.186. 11926

Vossen, H. G., \& Valkenburg, P. M. (2016). Do social media foster or curtail adolescents" empathy? A longitudinal study. Computers in Human Behavior, 63, 118-124. https://doi.org/10.1016/j.chb.2016.05.040

Wakefield, R. L., \& Whitten, D. (2006). Mobile computing: A user study on hedonic/utilitarian mobile device usage. European Journal of Information Systems, 15(3), 292-300. https://doi.org/10.1057/palgrave.ejis. 3000619

Wang, G., Wang, B., Wang, T., Nika, A., Zheng, H., \& Zhao, B. Y. (2014, November). Whispers in the dark: analysis of an anonymous social network. In Proceedings of the 2014 Conference on Internet Measurement Conference (pp. 137-150). https://doi.org/10.1145/2663716.2663728

Wirtz, B. W., \& Göttel, V. (2016). Technology acceptance in social media: review, synthesis and directions for future empirical research. Journal of Electronic Commerce Research, 17(2), 97. http://www.jecr.org/sites/ default/files/17_2Paper1.pdf

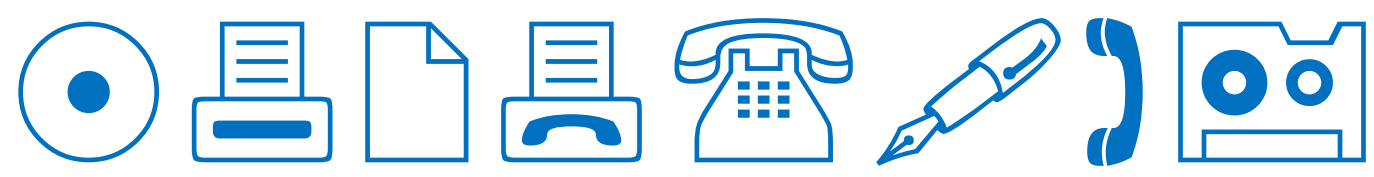

